\title{
SMc01553 is the sixth acyl carrier protein in Sinorhizobium meliloti 1021
}

Correspondence

Isabel M. López-Lara isabel@ccg.unam.mx

Received 7 August 2009

Revised 29 September 2009

Accepted 30 September 2009

\author{
Yadira Dávila-Martínez, ${ }^{1}$ Ana Laura Ramos-Vega, ${ }^{1}$ \\ Sandra Contreras-Martínez, ${ }^{2}$ Sergio Encarnación, ${ }^{2}$ Otto Geiger ${ }^{1}$ \\ and Isabel M. López-Lara ${ }^{1}$
}

\begin{abstract}
${ }^{1}$ Programa de Ecología Genómica, Centro de Ciencias Genómicas, Universidad Nacional Autónoma de México, Apdo. Postal 565-A, Cuernavaca, Morelos, C.P. 62251, Mexico

${ }^{2}$ Programa de Genómica Funcional de Procariontes, Centro de Ciencias Genómicas, Universidad Nacional Autónoma de México, Apdo. Postal 565-A, Cuernavaca, Morelos, C.P. 62251, Mexico
\end{abstract}

\begin{abstract}
Acyl carrier proteins (ACPs) are required for the transfer of acyl intermediates during fatty acid and polyketide syntheses. In Sinorhizobium meliloti 1021 there are five known ACPs: AcpP, NodF, AcpXL, the ACP domain in RkpA and SMb20651. The genome sequence of S. meliloti 1021 also reveals the ORF SMc01553, annotated as a putative ACP. smc01553 is part of a 6.6 kb DNA region that is duplicated in the chromosome and in the pSymb plasmid, the result of a recent duplication event. SMc01553 overexpressed in Escherichia coli was labelled in vivo with $\left[{ }^{3} \mathrm{H}\right] \beta$-alanine, a biosynthetic building block of the $4^{\prime}$-phosphopantetheine prosthetic group of ACPs. The purified SMc01553 was modified with 4'-phosphopantetheine in the presence of $S$. meliloti holo-ACP synthase, and this modification resulted in a major conformational change of the protein structure, since the holo-form runs faster in native PAGE than the apo-form. SMc01553 could not be loaded with a malonyl group by malonyl-CoA-ACP transacylase from $S$. meliloti. Using RT-PCR we could show the presence of mRNA for SMc01553 and of the duplicated ORF $\mathrm{SMb} 22007$ in cultures of $S$. meliloti. However, a mutant in which the two duplicated regions were deleted did not show any different phenotype with respect to the wild-type in the free-living or symbiotic lifestyle.
\end{abstract}

\section{INTRODUCTION}

Acyl carrier proteins (ACPs) are small acidic proteins containing the $4^{\prime}$-phosphopantetheine prosthetic group, to which fatty acyl chains are linked as thioesters during fatty acid and polyketide syntheses. ACPs act as carriers of acyl intermediates, which are shuttled from one enzyme to another. Apo-ACP is converted to the active protein by holo-ACP synthase (AcpS), which transfers the 4'-phosphopantetheine from coenzyme A (CoA) to apo-ACP (Flugel et al., 2000; Lambalot et al., 1996), thereby converting it to the functional holo-ACP. ACPs exist as a domain within large multifunctional fatty acid or polyketide synthase (PKS) proteins (type I), or as a small monomeric protein in the system for fatty acid biosynthesis in bacteria and plastids [type II fatty acid synthase (FAS)] and in the dissociated PKSs (type II PKS). Acyl-ACPs in bacteria appear to interact with a great diversity of enzymes to provide a broad array of products containing fatty acids,

Abbreviations: ACP, acyl carrier protein; DOC, sodium deoxycholate; FAS, fatty acid synthase; KPS, K-antigen; MBOAT, membrane-bound Oacyltransferase; PKS, polyketide synthase. such as phospholipids, lipid A, acylhomoserine lactones and nodulation factors (reviewed by Byers \& Gong, 2007).

The fatty acyl chains in primary metabolism and the scaffolds of polyketide secondary metabolites are assembled by elongation of a small number of carboxylic acid building blocks. Malonyl-CoA is the extender unit in fatty acid biosynthesis. In the type II FAS, the enzyme malonyl$\mathrm{CoA}$ : ACP transacylase (FabD) transfers the malonyl group from malonyl-CoA to holo-ACP, resulting in the formation of malonyl-ACP, which enters each elongation step (Rock, 2008). The FabD enzyme of Streptomyces glaucescens, which catalyses the conversion of malonyl-CoA to malonyl-ACP for fatty acid biosynthesis, has been shown to be also active with the ACPs of type II PKS (Florova et al., 2002). Polyketides comprise a large class of structurally diverse natural products and, although malonyl-CoA is a common extender unit used by all types of PKSs, one important source of the structural diversity of polyketides is the variety of extender units used. These extender units can be divided into two classes depending upon whether they are linked to CoA or to an ACP (reviewed by Chan et al., 2009). The set of genes required for the biosynthesis of the ACP-linked extender units are usually found within or 
flanking the associated biosynthetic gene clusters (Chan et al., 2009).

In Escherichia coli K-12 there is a single and absolutely essential ACP, which is produced constitutively from the acpP gene (Rawlings \& Cronan, 1992). In rhizobia, besides the constitutive acyl carrier protein (AcpP) involved in the biosynthesis and transfer of common fatty acids, there are at least three specialized ACPs: (1) the flavonoid-inducible nodulation protein NodF (Geiger et al., 1991); (2) the $\mathrm{RkpF}$ protein, which is required for the biosynthesis of rhizobial capsular polysaccharides (Epple et al., 1998); and (3) AcpXL, which transfers 27-hydroxyoctacosanoic acid to a sugar backbone during lipid A biosynthesis (Brozek et al., 1996). RkpF was first identified as the sixth gene in the chromosomal region rpk-1 $(r k p A B C D E F)$ in the strain Sinorhizobium meliloti Rm41. However, in the available genome of $S$. meliloti 1021, rkpABCDEF are fused into a single ORF, now named $r k p A$, and in this case RkpF corresponds to an ACP domain in a large multifunctional protein with homology to type I PKSs (Geiger \& LópezLara, 2002; Becker et al., 2005). Furthermore, the genome sequence of S. meliloti 1021 (Galibert et al., 2001) reveals the existence of two additional putative ACPs, SMb20651 and SMc01553 (Geiger \& López-Lara, 2002). Recently, we have characterized SMb20651 as the fifth functional ACP in S. meliloti 1021. We showed that SMb20651 actively participates in an acyl-involving metabolic step in wildtype S. meliloti, but no phenotype was found in mutants with a deletion in smb20651 (Ramos-Vega et al., 2009). Mutants of $S$. meliloti in nodF produce Nod factors lacking $\alpha, \beta$-unsaturated fatty acids and exhibit a significantly reduced capacity to elicit infection thread formation in alfalfa, although they can form nitrogen-fixing nodules (Ardourel et al., 1994). Mutants of S. meliloti in acpXL have increased sensitivity to a number of different stresses compared with the wild-type (Ferguson et al., 2005). These mutants can still form a successful nitrogen-fixing symbiosis with alfalfa, but are less competitive in symbiosis than the parent strain (Ferguson et al., 2005; Sharypova et al., 2003). Furthermore, acpXL mutants of $S$. meliloti are seriously affected in early and late stages of bacteroid development (Haag et al., 2009).

The other ORF of S. meliloti 1021 that presumably encodes a novel ACP ( $\mathrm{SMc} 01553$ ) is located on the chromosome. Interestingly, a very recent gene transfer event involving smc01553 occurred in S. meliloti 1021, where a $6.6 \mathrm{~kb}$ segment of DNA, including smc01553, appears to have been duplicated between the chromosomal DNA and the pSymb megaplasmid, giving this organism two copies of the gene encoding the putative new ACP and its adjacent genes (Galibert et al., 2001; Fig. 1a). SMc01553 is assigned in the genome project as a putative ACP, and presents all the typical characteristics of ACPs, such as small size (82 aa), acidic pI (4.6), and a phosphopantetheine-binding motif. In the pSymb fragment, the ORF encoding the ACP is $\mathrm{SMb} 22007$, which is $100 \%$ identical to $\mathrm{SMc01553}$ but has an additional glutamine at the $\mathrm{C}$ terminus of the protein. The genes belonging to the duplicated DNA region are schematically represented in Fig. 1(a). SMc01550 and SMc01552, as well as the respective paralogous SMb21013 and SMb20842, are hypothetical proteins. SMc01551 and SMb20843 have homology to membrane-bound O-acyltransferases (MBOATs). All characterized members of the MBOAT superfamily encode enzymes that transfer organic acids, typically fatty acids, onto hydroxyl groups of membrane-embedded targets (Hofmann, 2000). SMc01551 has been named in the genome as AlgI, and in experiments on natural genomic design carried out in $S$. meliloti it has been found that the site of cointegration of the pSymA-pSymB replicon to the chromosome corresponds to the reiterated algI genes (Guo et al., 2003). SMc01554 is a protein of 651 aa that shows homology along the whole amino acid sequence to the unusually long FkbH homologues Tmn16 and ChlD1. Recently, it has been shown in vitro that Tmn16 and ChlD1 covalently tether the substrate 1,3-bisphosphoglycerate to a dedicated $\mathrm{ACP}$ and dephosphorylate it, forming the corresponding glyceryl-ACP (Sun et al., 2008). In the pSymb plasmid, the DNA with homology to smc01554 encodes two ORFs that are probably pseudogenes (Fig. 1a).

In only a few phylogenetically unrelated bacteria have ORFs that encode homologues to SMc01553 and SMc01554 been found and, except for the case of Frankia sp. EAN1pec, a gene encoding an MBOAT is situated in the vicinity (Fig. 1b). The scattered distribution of the region in only certain species of the proteobacteria, verrumicrobia, acidobacteria and actinobacteria (Fig. 1b) indicates that in most of these cases the DNA fragment was acquired by horizontal gene transfer.

Here, we present the characterization of the protein $\mathrm{SMc} 01553$ as an ACP. SMc01553 was overproduced as insoluble inclusion bodies and the renatured recombinant protein can be converted to the holo-form. SMc01553 could not be loaded with the usual extender unit malonylCoA using the enzyme FabD of S. meliloti. A mutant was created in which both duplicated regions were deleted, but no phenotype was found in relation to the wild-type in the free-living conditions tested or in symbiosis with alfalfa.

\section{METHODS}

Bacteria and growth conditions. Table 1 lists the bacterial strains and plasmids used in this work. E. coli was grown at $30{ }^{\circ} \mathrm{C}$ in LuriaBertani (LB) medium (Sambrook \& Russell, 2001), or in M9 minimal broth (Miller, 1972) in the case of $\left[{ }^{3} \mathrm{H}\right] \beta$-alanine labelling assays. $S$. meliloti strains were grown at $30{ }^{\circ} \mathrm{C}$ either in complex tryptone yeast (TY) broth supplemented with $4.5 \mathrm{mM} \mathrm{CaCl}_{2}$ (Beringer, 1974) or in the following minimal media: M9 supplemented with $2 \mu \mathrm{g}$ biotin $\mathrm{ml}^{-1}$ and with succinate $(10 \mathrm{mM})$ replacing glucose as the carbon source, Sherwood medium (Sherwood, 1970) with succinate (8.3 $\mathrm{mM}$ ) replacing mannitol as the carbon source, or Robertsen medium (Robertsen et al. 1981). Antibiotics were added, when required, at the following final concentrations $\left(\mu \mathrm{g} \mathrm{ml}^{-1}\right)$ : carbenicillin, 100; chloramphenicol, 20; kanamycin, 50; gentamicin, 20; spectinomycin, 200; tetracycline, 20 for E. coli, and neomycin, 200; 
(a)

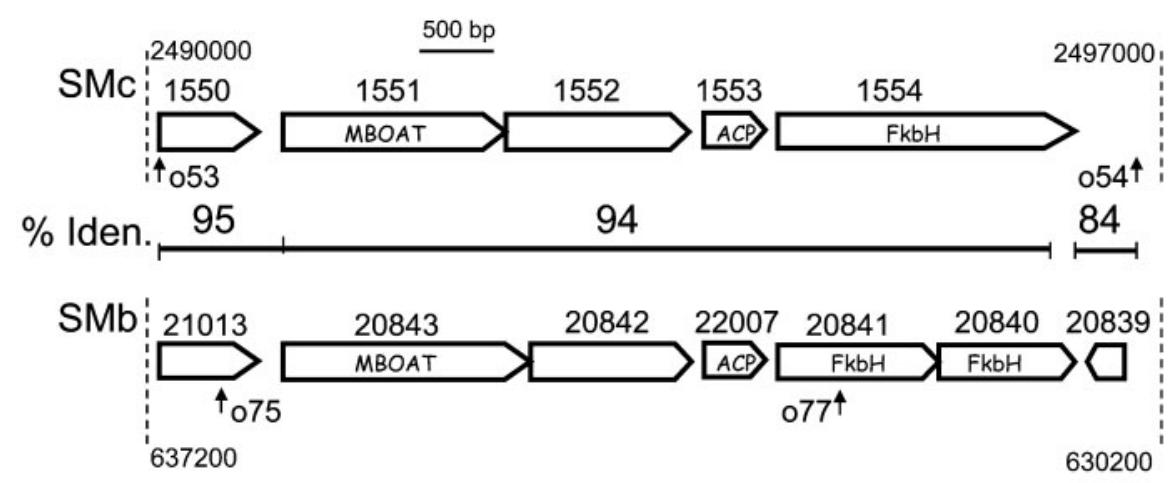

(b)

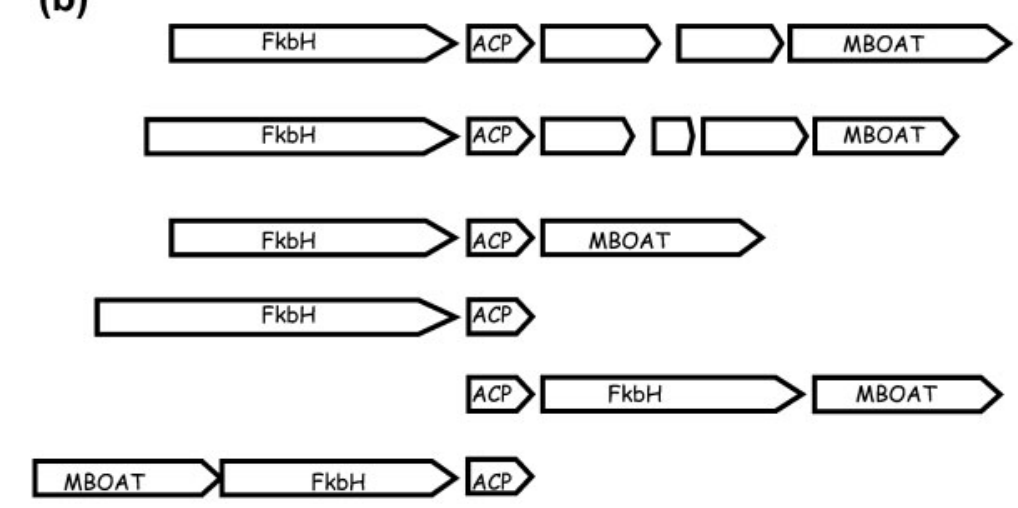

Species

(bacterial group)

Helicobacter bilis ATCC 43879

( $\varepsilon$-proteobacteria)

Bacterium Ellin514

(Verrumicrobia)

Solibacter usitatus Ellin6076

(Acidobacteria)

Frankia sp. EAN1pec

(Acitinobacteria)

Xanthobacter autotrophicus Py2

( $\alpha$-proteobacteria)

Pseudomonas stutzeri A1501

$(\gamma$-proteobacteria)

\section{(c)}



Fig. 1. Genetic organization around the gene encoding SMc01553 and selected SMc01553 homologues in different organisms. (a) Duplicated DNA regions in S. meliloti 1021. Coordinates of the fragments in the S. meliloti genome are indicated with dashed lines and percentages of identity (\% Iden.) at the DNA level are indicated on the line between the two fragments. The DNA region located between oligonucleotides 053 and 054 was deleted in mutant YD101, the region located between oligonucleotides 075 and 077 was deleted in mutant YD102, and both regions were deleted in mutant YD103. (b) Representative homologues in the bacterial species indicated on the right. Nomenclature used in (a) and (b): ACP, acyl carrier protein; FkbH, FkbH-like protein; MBOAT, membrane bound O-acyltransferase. (c) RT-PCR expression of smc01553 and smb22007 analysed in a 2\% agarose gel. Lanes: 1, 100 bp molecular mass marker; 2 and 6, DNA from S. meliloti 1021; 3, RT-PCR using RNA isolated from YD101 mutant; 4, RT-PCR using RNA isolated from YD103 (double mutant); 5, RNA from S. meliloti 1021 (negative control); 7, RT-PCR using RNA isolated from YD102; 8, RNA from YD101; 9, RNA from YD103; 10, RT-PCR using RNA from S. meliloti 1021. The oligonucleotide primers used were smc01553F and smc01553R (Table 2). 
Table 1. Bacterial strains and plasmids used in this study

$\mathrm{Sm}^{\mathrm{R}}, \mathrm{Kn}^{\mathrm{R}}, \mathrm{Cb}^{\mathrm{R}}, \mathrm{Cm}^{\mathrm{R}}, \mathrm{Gm}^{\mathrm{R}}$ and $\mathrm{Spc}^{\mathrm{R}}$ : streptomycin, kanamycin, carbenicillin, chloramphenicol, gentamicin and spectinomycin resistance, respectively. Subscript ${ }_{S m}$ denotes genes from S. meliloti 1021. Plasmids used and made for construction of mutants are specified in Methods.

\begin{tabular}{|c|c|c|}
\hline Strain or plasmid & Relevant characteristics & Source or reference \\
\hline \multicolumn{3}{|l|}{ E. coli strains } \\
\hline $\mathrm{DH} 5 \alpha$ & Host used for cloning & Bethesda Research Laboratory \\
\hline OG7001 & panD mutant of BL21(DE3), $\beta$-alanine auxotroph & Epple et al. (1998) \\
\hline \multicolumn{3}{|l|}{ S. meliloti strains } \\
\hline 1021 & $\mathrm{Sm}^{\mathrm{R}}$ of SU47 wild-type & Galibert et al. (2001) \\
\hline YD102 & Deletion of $4 \mathrm{~kb}$ in $\mathrm{pSymb}, \mathrm{Gm}^{\mathrm{R}}$ & This study \\
\hline YD103 & Double mutant, having deletions of both YD101 and YD102, $\mathrm{Spc}^{\mathrm{R}}, \mathrm{Gm}^{\mathrm{R}}$ & This study \\
\hline \multicolumn{3}{|l|}{ Plasmids } \\
\hline pET9a & Expression vector, $\mathrm{Kn}^{\mathrm{R}}$ & Studier et al. (1990) \\
\hline pET16b & Expression vector, $\mathrm{Cb}^{\mathrm{R}}$ & Studier et al. (1990) \\
\hline pLysS & Causes repression of $\mathrm{T} 7$ polymerase, $\mathrm{Cm}^{\mathrm{R}}$ & Studier et al. (1990) \\
\hline pAL20651 & smb20651 in pET9a & Ramos-Vega et al. (2009) \\
\hline pCSF07 & $\operatorname{nodF}_{S m}$ in pET9a & Ramos-Vega et al. (2009) \\
\hline pAL01553 & smc01553 in pET9a, $\mathrm{Kn}^{\mathrm{R}}$ & This study \\
\hline pAL07 & $a c p X L_{S m}$ in $\mathrm{pET} 9 \mathrm{a}, \mathrm{Kn}^{\mathrm{R}}$ & This study \\
\hline pYDM13 & smb22007 in pET9a, $\mathrm{Kn}^{\mathrm{R}}$ & This study \\
\hline pYDM29 & smc01553 in pET16b, $\mathrm{Cb}^{\mathrm{R}}$ & This study \\
\hline pYDM19 & acp domain of $r p k A_{S m}$ in pET9a, $\mathrm{Kn}^{\mathrm{R}}$ & This study \\
\hline
\end{tabular}

spectinomycin, 400; gentamicin, 70; streptomycin, 500; tetracycline, 4 for $S$. meliloti.

pK18mobsacB derivatives were mobilized into S. meliloti strains by diparental mating using the E. coli S17-1 donor strain as described by Simon et al. (1983).

DNA manipulations and RT-PCR analysis. Recombinant DNA techniques were carried out using standard procedures (Sambrook \& Russell, 2001). DNA and derived protein sequences were analysed using the National Center for Biotechnology Information (NCBI) BLAST network centre (Altschul et al., 1997). RNA was isolated from $2 \mathrm{ml}$ TY culture using the TRIzol reagent (Invitrogen) and treated with DNase I (Fermentas) as indicated by the manufacturers. cDNA was synthesized using a RevertAid $\mathrm{H}$ minus First Strand cDNA synthesis kit (Fermentas) as specified by the manufacturer.

Construction of expression plasmids. All genes were amplified from S. meliloti 1021 genomic DNA. Using specific oligonucleotides (Table 2), the genes smc01553, smb22007 and acpXL (smc04277) and the fragment encoding the ACP domain in RkpA were amplified and, after restriction with $\mathrm{NdeI}$ and BamHI, fragments were cloned into pET9a or pET16b (Studier et al., 1990) that had been digested with $\mathrm{NdeI}$ and BamHI. Names given to the respective expression plasmids are indicated in Table 1.

Construction of sinorhizobial mutants lacking SMc01553-type ACPs. First, the duplicated region of $6.6 \mathrm{~kb}$ present in the chromosome (coordinates 2490073 to 2496674) was exchanged with a spectinomycin resistance cassette (Fig. 1a). The oligonucleotide primers 052 and 053 (Table 2) were used in a PCR to amplify $1496 \mathrm{bp}$ of genomic DNA upstream of this region, introducing BamHI and HindIII sites (underlined in the table) into the PCR product. Similarly, the primers o54 and o55 (Table 2) were used to amplify $1594 \mathrm{bp}$ of genomic DNA downstream of the region, introducing HindIII and XhoI sites (underlined in the table) into this PCR product. After digestion with the respective enzymes, the $1496 \mathrm{bp}$ fragment was cloned into plasmid pBluescript SK + that had been digested with BamHI and HindIII, yielding the plasmid pYDM02. Then, the $1594 \mathrm{bp}$ fragment was cloned as HindIII/XhoI into plasmid pYDM02 that had been digested with HindIII and Xhol, yielding the plasmid pYDM03. A resistance cassette obtained as a HindIII fragment from plasmid pHY109 (Østeras et al., 1998) was inserted into pYDM03 that had been digested with HindIII to yield pYDM04. Plasmid pYDM04 was digested with BamHI and XhoI to reclone the regions usually flanking the $6.6 \mathrm{~kb}$ region, as well as the spectinomycin resistance gene located in between, as a $\mathrm{BamHI} / \mathrm{XhoI}$ fragment into the suicide vector pK18mobsacB (Schäfer et al., 1994) that had been digested with BamHI and SalI, yielding pYDM06. Plasmid pYDM06 was introduced into wild-type strain S. meliloti 1021, and double recombinants in which the spectinomycin resistance cassette replaced the $6.6 \mathrm{~kb}$ chromosomal region were obtained following the procedure described previously (Sohlenkamp et al., 2004). The mutant strain was named YD101.

A second mutant was created in which the gene smb22007, encoding the putative ACP in the pSymb plasmid, and surrounding areas were replaced by a gentamicin resistance cassette (Fig. 1a). A 4 kb DNA fragment was deleted comprising coordinates 633000-637000 in pSymb. The oligonucleotides o75 and o76 (Table 2) were used in a PCR to amplify $1610 \mathrm{bp}$ of genomic DNA upstream of the $4 \mathrm{~kb}$ fragment, introducing XbaI and HindIII sites (underlined in the 
Table 2. Oligonucleotide primers used in this study

For construction of expression plasmids, the forward primers incorporated an NdeI restriction site (underlined) overlapping the start codon of the respective gene. The reverse primers incorporated a BamHI restriction site (underlined) after the stop codon. For amplification of $s m b 22007$ the primers smc $01553 \mathrm{~F}$ and smb22007R were used.

\begin{tabular}{|c|c|}
\hline Primer & Sequence $\left(5^{\prime}-3^{\prime}\right)$ \\
\hline \multicolumn{2}{|c|}{ Primers used for construction of expression plasmids } \\
\hline smc01553F & AGGAATACATATGTCTGACCATCAACTTTATC \\
\hline smc01553R & AAAGGATCCTCAGTTCTGCTTGCGCTTGAC \\
\hline smb22007R & AAAGGATCCTATTGGTTCTGCTTGCGCTTGAC \\
\hline acpXLF & AGGAATACATATGCGCGTGACAGCTACATTC \\
\hline acpXLR & AAAGGATCCTCAACCCGCTTTTGCGGCC \\
\hline domainrkpAF & AGGAATACATATGATCGAAGGCAAATCGCC \\
\hline domainrkpAR & AAAGGATCCTCATTGACTCAGTGCTTTTTCC \\
\hline \multicolumn{2}{|c|}{ Primers used for mutagenesis } \\
\hline o52 & AAAGGATCCGCCGGTTCCCTTGAATGC \\
\hline o53 & ATAGTAAGCTTGGAAGCAGGAGCGGCAAACG \\
\hline o54 & ATAGTAAGCTTGCCCTCTCGCGATCACTGG \\
\hline o55 & ATAGTCTCGAGTCACGGCCACCGCCAGG \\
\hline o75 & AGCTCTAGACCCAATGACGGCGAGCGAGAC \\
\hline o76 & ACCCAAGCTTGCGTGGCTCCCTGCTGCGTCC \\
\hline o77 & ACCCAAGCTTGCCCGACTACGCCGCCACCAG \\
\hline o78 & ACCGCTCGAGCGGGTGGTCAGGTTGAACTGG \\
\hline
\end{tabular}

table) into the PCR product. Similarly, the primers o77 and o78 (Table 2) were used to amplify 1382 bp of genomic DNA downstream of the selected region (Fig. 1a), introducing HindIII and XhoI sites (underlined in the table) into the PCR product. After digestion with the respective enzymes, the $1610 \mathrm{bp}$ fragment was cloned into plasmid pBluescript SK + that had been digested with $X b a \mathrm{I}$ and HindIII, yielding the plasmid pYDM39. Then, the 1382 bp fragment was cloned as HindIII/XhoI into plasmid pYDM39 that had been digested with HindIII and XhoI, yielding the plasmid pYDM49. A gentamicin resistance cassette obtained as a HindIII fragment from plasmid pAC $\Omega-G m$ (Schweizer, 1993) was inserted into pYDM49 that had been digested with HindIII, yielding pYDM53. Plasmid pYDM53 was digested with $\mathrm{XbaI}$ and $\mathrm{XhoI}$ to reclone the regions usually flanking the deleted region and the gentamicin resistance gene located in between those regions as an $\mathrm{XbaI} / \mathrm{Xhol}$ fragment into the suicide vector pK18mobsacB that had been digested with XbaII and SalI, yielding pYDM55. Plasmid pYDM55 was introduced into wild-type strain S. meliloti 1021 and into mutant YD101 that lacks the chromosomal duplicated DNA region, and double recombinants in which the gentamicin resistance cassette replaced the selected region of pSymb were obtained following the procedure described previously (Sohlenkamp et al., 2004). The single mutant was named YD102, and the double mutant YD103. The correct genetic organization of the three mutants obtained was corroborated by Southern blot analysis.

Analysis of proteins. Proteins were analysed by $20 \%$ native PAGE (Jackowski \& Rock, 1983), by conformationally sensitive gels as previously described (Ramos-Vega et al., 2009), or by denaturing SDS-PAGE according to Schägger and von Jagow (1987) using $16.8 \%$ acrylamide in the separating gel. Gels were stained with Coomassie blue. Protein concentrations were determined by the method of Dulley \& Grieve (1975) using BSA (Sigma) as standard.

In vivo labelling with $\left[{ }^{3} \mathrm{H}\right] \boldsymbol{\beta}$-alanine. In vivo labelling of ACPs with $\left[{ }^{3} \mathrm{H}\right] \beta$-alanine, the biosynthetic precursor of $4^{\prime}$-phosphopantetheine, was carried out essentially as described previously using the $\beta$ - alanine auxotroph OG7001 (Epple et al., 1998; López-Lara \& Geiger, 2000).

Overproduction of ACPs in E. coli cultures and purification of AcpP. Cell-free extracts of E. coli BL21(DE3) pLysS overproducing the respective ACPs were obtained as previously described (RamosVega et al., 2009). Purified AcpP of S. meliloti was prepared as reported previously (López-Lara \& Geiger, 2000), with the exception that in the last step, AcpP was purified using PrepCell (model 491, Bio-Rad) containing a cylindrical $20 \%$ native polyacrylamide gel rather than by electroelution from preparative gels. Fractions containing AcpP were combined and concentrated using a Centricon YM-3 centrifugal concentrator (Amicon, Millipore).

Renaturation and purification of SMc01553. SMc01553 and HisSMc01553 were overproduced in E. coli mainly as insoluble proteins. After cells were disrupted by French press, extracts were centrifuged and pellets were resuspended in 10 volumes of washing buffer (50 mM Tris/ $\mathrm{HCl}, \mathrm{pH} 6.8,100 \mathrm{mM} \mathrm{KCl}$ ) and centrifuged for $10 \mathrm{~min}$ at $15000 \mathrm{~g}$ at $4{ }^{\circ} \mathrm{C}$. Solubilization of the inclusion body-containing pellet was achieved with $50 \mathrm{mM}$ Tris/ $\mathrm{HCl}, \mathrm{pH} 8,5 \mathrm{M}$ guanidine $\mathrm{HCl}$, $0.005 \%$ Tween 80 , and the solution was maintained at $8{ }^{\circ} \mathrm{C}$ overnight. To remove insoluble material, the solution was spun at $19000 \mathrm{~g}$ for $15 \mathrm{~min}$. The supernatant was diluted to a final $A_{280}$ of 0.1 in refolding buffer $(50 \mathrm{mM}$ Tris/ $\mathrm{HCl}, \mathrm{pH} 8,1 \mathrm{M}$ guanidine $\mathrm{HCl}$, $0.005 \%$ Tween $80,0.35 \mathrm{M}$ L-arginine, $2 \mathrm{mM}$ GSH, $0.02 \mathrm{mM}$ GSSG) and kept at $8{ }^{\circ} \mathrm{C}$ for $50-60 \mathrm{~h}$. After that, the Tween 80 concentration was adjusted to $0.05 \%$ and the resulting solution was dialysed against $50 \mathrm{mM}$ Tris/HCl, pH 8, $50 \mathrm{mM} \mathrm{NaCl}, 0.05 \%$ Tween 80. After centrifugation of the solution to remove precipitates, SMc01553 protein was concentrated using a Centricon YM-3.

In the case of His-SMc01553, after adjusting the Tween concentration to $0.05 \%$, the protein solution was dialysed against start buffer (20 mM sodium phosphate, $0.5 \mathrm{M} \mathrm{NaCl}, 10 \mathrm{mM}$ imidazole, $\mathrm{pH} 7.4$ ) and afterwards further purified using a $1 \mathrm{ml} \mathrm{Ni}^{2+}$ agarose column 
(Hi Trap; Pharmacia Biotech) following the recommended standard method.

\section{Generation of polyclonal antiserum against the ACP SMc01553 and Western blot analysis. Antiserum against the purified His- SMc01553 was raised in a white New Zealand rabbit that had been injected four times, each with a 1:1 mixture of Freund's complete or incomplete adjuvant (Roche) together with $150 \mu \mathrm{g}$ His-SMc01553 antigen protein in $137 \mathrm{mM} \mathrm{NaCl}, 2.7 \mathrm{mM} \mathrm{KCl}, 4.3 \mathrm{mM} \mathrm{Na}{ }_{2} \mathrm{HPO}_{4}$

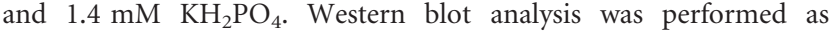 described previously (Ramos-Vega et al., 2009), using anti-His- SMc01553 serum diluted 1000 times.}

Enzymatic assays and MS. In vitro modification of apo-ACPs to holo-ACPs and in vitro malonylation of holo-ACPs were performed as previously described (Ramos-Vega et al., 2009). Quantitative conversion of apo-SMc01553 to holo-SMc01553 was performed as reported previously (Epple et al., 1998). MALDI-TOF MS was performed using a Bruker Daltonics Autoflex operated in the linear mode. Protein mixtures were prepared and spectra were obtained as described previously (Ramos-Vega et al., 2009).

Phenotypes of mutants. Zones of inhibition, using the filter-disk assay with the detergents SDS and sodium deoxycholate (DOC), were measured as previously described (Ferguson et al., 2002; Ramos-Vega et al., 2009). The profile of rhizobial K-antigens (KPSs) was analysed by $18 \%$ DOC-PAGE following the procedure described by Reuhs et al. (1998). Alfalfa (Medicago sativa L.) plants were grown in a nitrogenfree medium as described previously (Olivares et al., 1980). Nitrogen fixation was determined by examining acetylene reduction using GC (Burris, 1972).

\section{RESULTS AND DISCUSSION}

\section{Overproduction of the six different ACPs of $\mathbf{S}$. meliloti 1021}

In order to have the possibility of purifying all ACPs present in S. meliloti 1021, plasmids for the overproduction of AcpXL, the ACP domain of RkpA and SMc01553 were constructed in this study. Although all ACPs were predicted to be soluble proteins with similar characteristics, the total amount of the respective ACP present in cell extracts varied greatly (Fig. 2a). In particular, little soluble SMc01553 was detected in cell extracts (Fig. 2a, lane 6). Cell extracts of E. coli overproducing SMc01553 were whitish, indicating that SMc01553 was overproduced as inclusion bodies. The analysis of pellets after low-speed centrifugation showed indeed that SMc01553 was mainly produced as inclusion bodies (Fig. 2b), and only a minor proportion of the protein was obtained as soluble protein (Fig. 2a, lane 6). Several parameters of the culture for overproduction of SMc01553 were varied, but in all cases the protein was mainly obtained as inclusion bodies (data not shown). Therefore, SMc01553 was purified from the inclusion bodies through a process of denaturation and renaturation. To our knowledge, this is the first bacterial ACP that, when overproduced, forms inclusion bodies. Although we observed that RkpF was also overproduced in part as inclusion bodies (results not shown), the amount of soluble protein obtained was enough for purification from the soluble fraction (Epple et al., 1998). We have also amplified smb22007, which encodes a protein identical to SMc01553 with only the addition of the amino acid glutamine at the carboxy-terminus. However, as overproduced SMb22007 also formed mainly inclusion bodies (results not shown), the rest of the work was continued with SMc01553.

\section{SMc01553 is modified in vivo and in vitro with $4^{\prime}$ - phosphopantetheine}

ACPs are functional when substituted with the $4^{\prime}$ phosphopantetheine prosthetic group. Cell-free extracts of E. coli OG7001(pLysS), carrying either empty pET9a or plasmids that allowed overproduction of NodF, RkpF or SMc01553, which had been grown in the presence of $\left[{ }^{3} \mathrm{H}\right] \beta$ alanine were analysed by PAGE and subsequent autoradiography. A Coomassie-stained gel showed bands in cell crude extracts corresponding to the overproduction in $E$. coli of NodF from S. meliloti 1021 and of RkpF from $S$. meliloti Rm41 (Fig. 3a, lanes 1 and 2) that efficiently incorporated $\left[{ }^{3} \mathrm{H}\right] \beta$-alanine (Fig. 3b). Although SMc01553
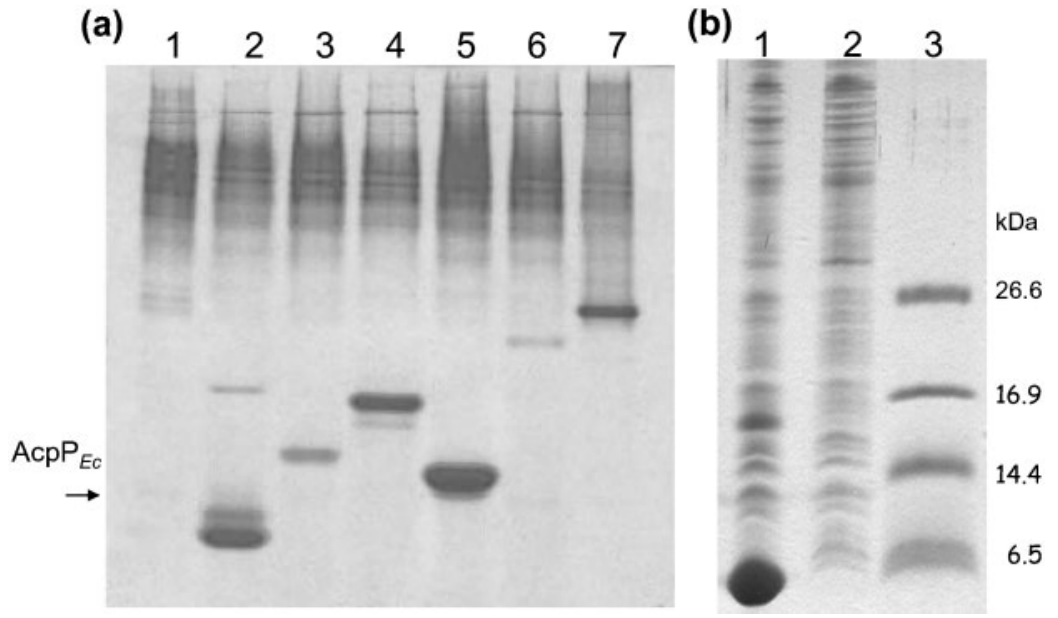

Fig. 2. Overproduction of $S$. meliloti 1021 ACPs in E. coli $(E C)$. Analysis of cell-free extracts from $E$. coli separated by $20 \%$ native PAGE (a) or of insoluble inclusion bodies separated in a $16.8 \%$ SDS Schägger and von Jagow gel (b) stained with Coomassie blue. In (a) the overproduced ACPs were: lane 1, none (E. coli containing the $\mathrm{pET9a}$ vector); 2, AcpP; 3, NodF; 4, AcpXL; 5, SMb20651; 6, SMc01553; 7, ACP domain of RkpA. (b) Pellets after obtaining the crude extract from E. coli overproducing SMc01553 (lane 1) or from E. coli carrying the vector pET9a (lane 2); lane 3, molecular mass marker. In each lane the equivalent of $\sim 0.25 \mathrm{ml}$ culture was loaded. 


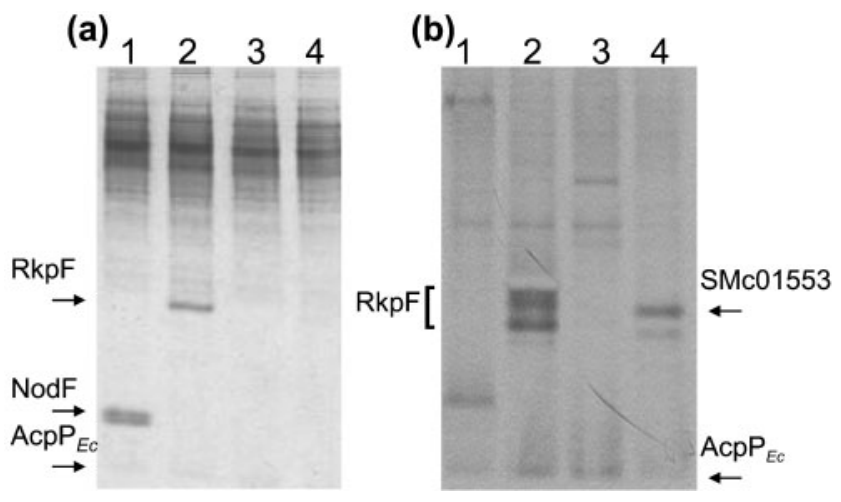

Fig. 3. Overproduction of $S$. meliloti ACPs in E. coli (EC) OG7001 (pLysS). Analysis of cell extracts from E. coli strains overproducing NodF, RkpF and SMc01553. (a) Proteins separated by $20 \%$ native PAGE and stained with Coomassie blue. (b) Autoradiogram after labelling with $\left[{ }^{3} \mathrm{H}\right] \beta$-alanine. In (a) and (b) gels were loaded with cell-free extracts of $E$. coli overproducing: NodF (lane 1), RkpF (lane 2), no ACPs (E. coli strain carrying pET9a) (lane 3) and SMc01553 (lane 4). Note that the amount of soluble $\mathrm{SMc01553}$ is not enough to be seen in a Coomassie blue-stained gel [lane 4 in (a)] but the $\left[{ }^{3} \mathrm{H}\right]$-labelled protein could be observed in a parallel protein sample treated in the same way (b). The bands corresponding to E. coli AcpP, NodF, RkpF and SMc01553 are indicated.

was poorly overproduced as a soluble protein, it was efficiently labelled with $\left[{ }^{3} \mathrm{H}\right] \beta$-alanine (Fig. 3, lanes 4), indicating the formation of holo-SMc01553. An enzyme activity present in E. coli, presumably AcpS, can modify SMc01553 post-translationally by adding the prosthetic group.

In order to test whether we could quantitatively convert apo-SMc01553 to holo-SMc01553, we incubated the purified apo-SMc01553 protein, obtained after the process of denaturation and renaturation, in the presence of CoA and His-AcpS from S. meliloti (Ramos-Vega et al., 2009). The time-course of a quantitative conversion of apoSMc01553 into holo-SMc01553 could readily be followed (Fig. 4). If the AcpS activity is inhibited by the presence of the chelating agent EGTA, apo-SMc01553 is not converted to holo-SMc01553. During analysis with native PAGE, even apo-SMc01553 protein and holo-SMc01553 protein migrate differently. Holo-SMc01553 migrates faster on native $20 \%$ PAGE than apo-SMc01553 (Fig. 4), suggesting a more compact structure for holo-SMc01553 than for apo-SMc01553. In a similar manner, holo-RkpF migrates faster than apo-RkpF in $20 \%$ native PAGE (Epple et al., 1998) and, as expected, the holo-form of the ACP domain of RkpA also ran faster than its apo-form in the same types of gels (results not shown).

Analysis of purified SMc01553 by MALDI-TOF MS showed a major peak at $\mathrm{m} / \mathrm{z} 9221.19$ and a second peak at $\mathrm{m} / \mathrm{z} 9351.85$ (Fig. 5a), in agreement with the expected

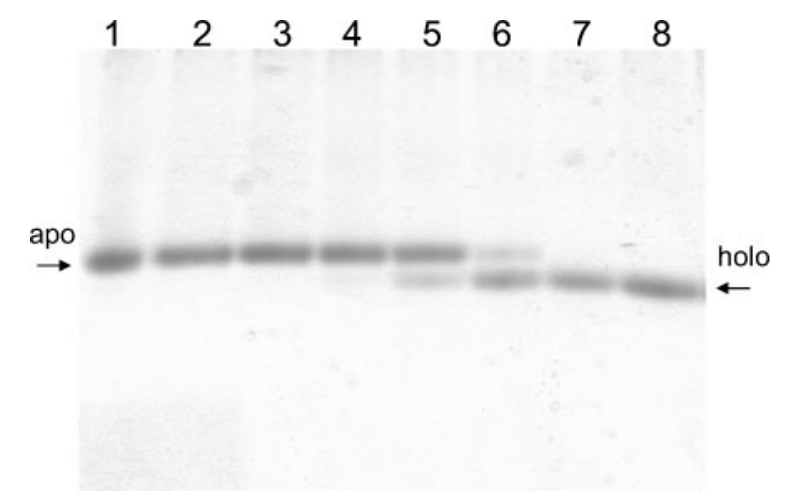

Fig. 4. Quantitative conversion of apo-SMc01553 into holoSMc01553 protein. Apo-SMc01553 was incubated with CoA in the presence His-AcpS, and the reaction was stopped with EGTA after different incubation times. A Coomassie-stained gel after native $20 \%$ PAGE is shown. The various lanes show reaction mixture lacking His-AcpS (lane 1), reaction mixture in which EGTA was added before the incubation was started (incubation time, $128 \mathrm{~min}$ ) (lane 2), $0 \mathrm{~min}$ incubation (lane 3), $8 \mathrm{~min}$ incubation (lane 4), 16 min incubation (lane 5), 32 min incubation (lane 6), 64 min incubation (lane 7) and 128 min incubation (lane 8). The positions of apo-SMc01553 (apo) and holo-SMc01553 (holo) are indicated.

masses for species of SMc01553 lacking (9221.41) or retaining the $\mathrm{N}$ terminal methionine (9352.60). SMc01553 that had been incubated with His-AcpS yielded masses of 9560.40 and 9691.23 (Fig. 5b), which correspond to increases of 339.21 and 339.38 atomic mass units (amu) with respect to the peaks observed in the untreated samples. These differences are consistent with the expected 339 amu for the $4^{\prime}$-phosphopantetheine addition, indicating that His-AcpS-treated SMc01553 is carrying the prosthetic group typical for ACPs. Preliminary data also detected an increase of about $339 \mathrm{amu}$ in samples of NodF, AcpXL and the ACP domain of RkpA that had been treated with His-AcpS (data not shown). Therefore, AcpS of $S$. meliloti is able to modify all ACPs present in this strain.

\section{SMc01553 is not malonylated by FabD}

Malonyl-CoA:ACP transacylase (FabD) is the enzyme responsible for the transfer of the malonyl group from malonyl-CoA to holo-ACP, resulting in the formation of malonyl-ACP. Although the ACP SMb20651 is specifically modified by the enzyme SMb20650, it could also be loaded in vitro with a malonyl group using malonyl-CoA and HisFadD from S. meliloti (Ramos-Vega et al., 2009). We tested whether SMc01553 could be modified with His-FabD. As a positive control, the AcpP of S. meliloti was used. Conformationally sensitive PAGE showed a slower-migrating form of AcpP that appeared only when the protein was incubated with malonyl-CoA and His-FabD (Fig. 6a). However, holo-SMc01553 that had been treated in the same way did not show any change in mobility in native 

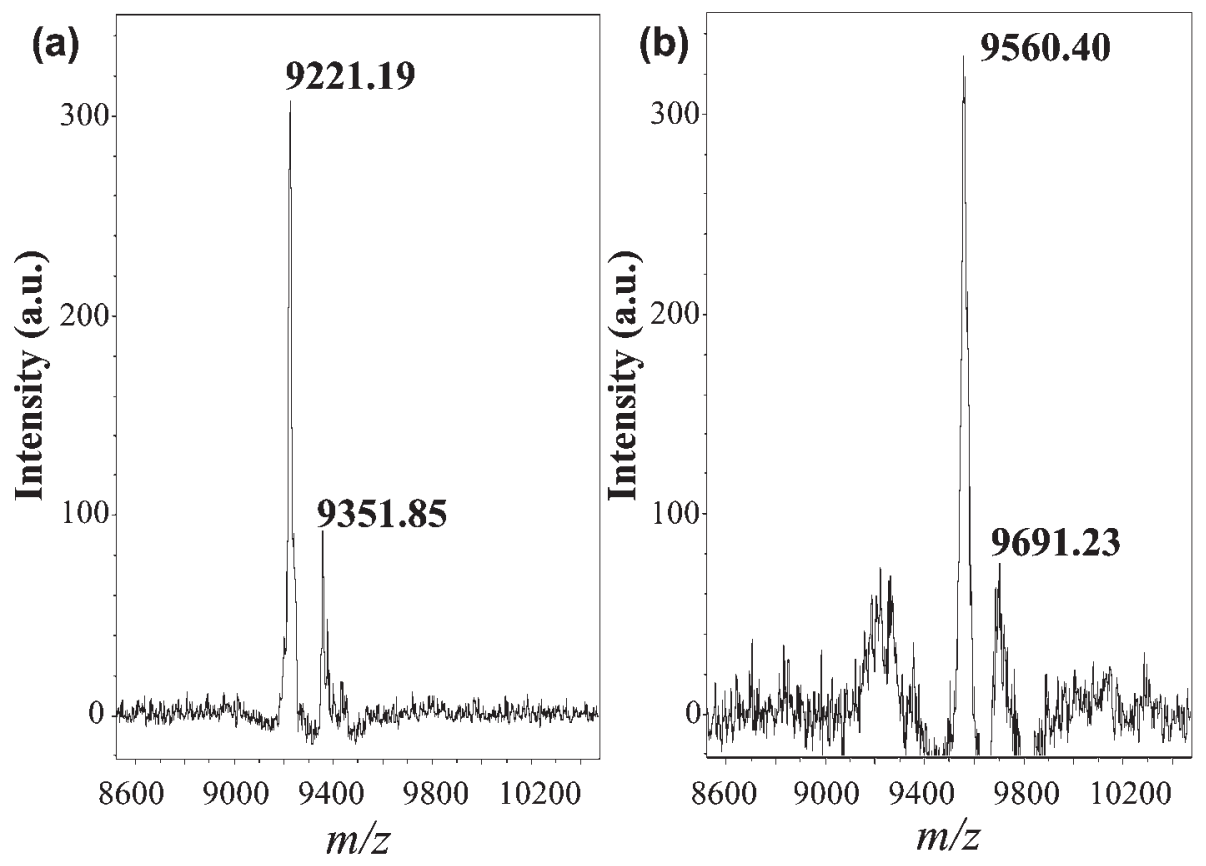

Fig. 5. In vitro 4 '-phosphopantetheinylation of SMc01553 observed by MALDI-TOF MS. Spectra of SMc01553 incubated with $\mathrm{CoA}$ in the absence (a) or presence (b) of purified S. meliloti His-AcpS. Intensity is given in arbitrary units (a.u.).

PAGE (Fig. 6b) or in conformationally sensitive PAGE containing concentrations of urea ranging from 0.5 to 3.2 M. Analysis by MS of holo-SMc01553 that had been treated with His-FabD in the presence of malonyl-CoA did not show any difference from the spectra of non-treated holo-SMc01553, and a peak corresponding to malonyl-

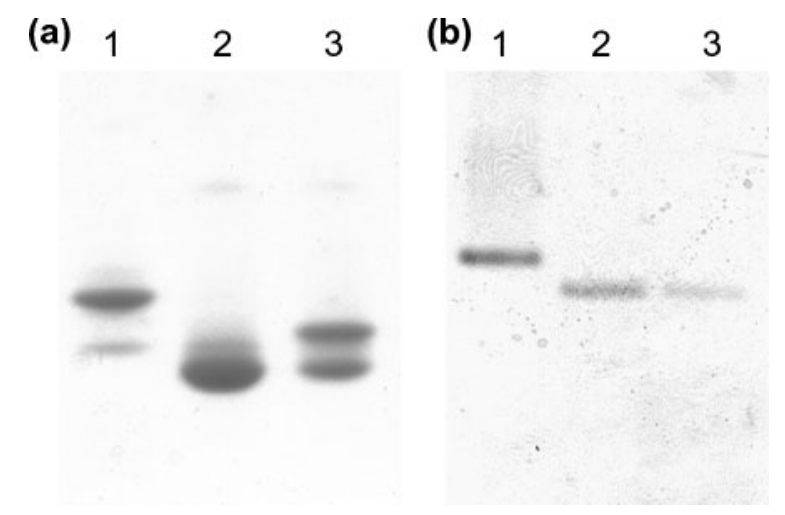

Fig. 6. Malonylation assay of sinorhizobial AcpP or SMc01553. AcpP was separated by conformationally sensitive PAGE in gels containing 3.2 M urea (a), whereas SMc01553 was analysed by $20 \%$ native PAGE (b). Gels were visualized by staining with Coomassie blue. Proteins in (a): apo-AcpP (lane 1), holo-AcpP (lane 2) and holo-AcpP assay with malonyl-CoA in the presence of FadD (lane 3). Proteins in (b): apo-SMc01553 (lane 1), holoSMc01553 (lane 2) and holo-SMc01553 assay with malonyl-CoA in the presence of FadD (lane 3).
SMc01553 could not be detected. In samples of holo-AcpP treated in parallel with His-FabD and malonyl-CoA, a clear peak was observed that corresponded to the expected increase of $86 \mathrm{amu}$ for the addition of the malonyl group to holo-AcpP (results not shown). These results suggest that SMc01553 is not a substrate of FabD and probably cannot be loaded with the malonyl group. The genes smc01553 and smc01554 are predicted to form an operon. Also, in genomes that contain homologues for SMc01553, the gene encoding such a homologue is always located next to a gene encoding a homologue of SMc01554 (Fig. 1b). SMc01554 and the homologous proteins derived from genomes shown in Fig. 1(b) are members of the $\mathrm{FkbH}$ family of enzymes, and for some of those members it has been shown in vitro that they modify a dedicated ACP with an unusual extender unit (Sun et al., 2008; Wu et al., 2000). It is likely that SMc01553 is loaded by SMc01554 with a specific moiety, and experiments are under way to determine whether SMc01553 can be modified by $\mathrm{SMc01554}$ in vivo.

\section{Phenotypic characterization of sinorhizobial mutants lacking SMc01553-type ACPs}

None of the three mutants constructed in this study displayed growth differences with respect to wild-type $S$. meliloti 1021 when grown on TY medium or in any of the minimal media (M9, Robertsen or Sherwood). Using filter disk assays, no difference of sensitivity was found to the detergents SDS or DOC. The DNA region deleted in pSymb is in between two paralogues of $r k p Z$ and next to 
the gene cluster 2 of S. meliloti 1021 involved in the biosynthesis of KPS (Becker et al., 2005). Analysis by DOC-PAGE did not show any difference in the profiles of the different mutants in relation to the wild-type (results not shown). However, a small change in the structure of such a polysaccharide might not be detected by this technique.

With the polyclonal antibody raised against His-SMc01553, SMc01553 could not be detected in cell extracts of the wildtype strain grown in any of the media mentioned above. However, RT-PCR did reveal the presence of mRNA of smc01553 or $s m b 22007$ in the case of the wild-type and each of the single mutants, while such a transcript was not present in RNA extracted from the double mutant YD103 (Fig. 1c). The RT-PCR results obtained from the analysis of the single mutants YD101 and YD102 showed, respectively, the expression of smb22007 and smc01553 (Fig. 1c, lanes 3 and 7). An Affimetrix GeneChip containing the complete $S$. meliloti genome has shown that in TY-grown cells, smc01553 and smc01554 are among the two-thirds of putative coding regions that are expressed at above background levels (Barnett et al., 2004), confirming that these two genes are expressed under such growth conditions. SMc01553 and SMc01554, and perhaps SMc01551, seem to be part of a pathway for the synthesis of a secondary metabolite, but from the genome of S. meliloti 1021 it is not clear which other genes could be involved in such a pathway. Since these genes are the result of a recent event of horizontal gene transfer (Galibert et al., 2001), it is possible that only part of the genes required for the synthesis of such a metabolite were transferred.

Alfalfa plants were inoculated with either the parent strain 1021, each one of the mutants lacking either the chromosomal region or the region in pSymb, or the double mutant lacking both regions. No significant differences in the number of nodules or in the course of nodule development were observed (data not shown). After 40 days, the nitrogen-fixing ability was measured and no significant differences were observed (data not shown).

We have not found any phenotype in free-living or symbiotic conditions for the S. meliloti mutant lacking the DNA fragments encoding SMc01553 and SMb22007. Although more experiments need to be carried out to find possible functions encoded by these regions, it is possible that they contain only accessory DNA because these regions are the result of the duplication of DNA acquired by horizontal gene transfer. At this point it is not clear whether the products of the DNA of either region are responsible for the formation of a functional metabolite.

\section{ACKNOWLEDGEMENTS}

This work was supported by a grant from Consejo Nacional de Ciencia y Tecnología (CONACyT)/Mexico (49738-Q) with partial support from the Howard Hughes Medical Institute (HHMI 55003675). Y.D.-M. was supported during the $\mathrm{PhD}$ programme [Programa de Doctorado en Ciencias Biomédicas, Universidad
Nacional Autónoma de México (UNAM)] by scholarships from CONACyT and Dirección General de Estudios de Postgrado (UNAM).

\section{REFERENCES}

Altschul, S. F., Madden, T. L., Schäfer, A. A., Zhang, J., Zhang, Z., Miller, W. \& Lipman, D. J. (1997). Gapped BLAST and PSI-BLAST: a new generation of protein database search programs. Nucleic Acids Res 25, 3389-3402.

Ardourel, M., Demont, N., Debellé, F., Maillet, F., de Billy, F., Promé, J. C., Dénarié, J. \& Truchet, G. (1994). Rhizobium meliloti lipooligosaccharide nodulation factors: different structural requirements for bacterial entry into target root hair cells and induction of plant symbiotic developmental responses. Plant Cell 6, 1357-1374.

Barnett, M. J., Toman, C. J., Fisher, R. F. \& Long, S. R. (2004). A dualgenome symbiosis chip for coordinate study of signal exchange and development in a prokaryote-host interaction. Proc Natl Acad Sci U S A 101, 16636-16641.

Becker, A., Fraysse, N. \& Sharypova, L. (2005). Recent advances in studies on structure and symbiosis-related function of rhizobial Kantigens and lipopolysaccharides. Mol Plant Microbe Interact 18, 899905.

Beringer, J. E. (1974). R factor transfer in Rhizobium leguminosarum. J Gen Microbiol 84, 188-198.

Brozek, K. A., Carlson, R. W. \& Raetz, C. R. (1996). A special acyl carrier protein for transferring long hydroxylated fatty acids to lipid A in Rhizobium. J Biol Chem 271, 32126-32136.

Burris, R. H. (1972). Nitrogen fixation assay-methods and techniques. Methods Enzymol 24, 415-431.

Byers, D. M. \& Gong, H. (2007). Acyl carrier protein: structurefunction relationships in a conserved multifunctional protein family. Biochem Cell Biol 85, 649-662.

Chan, Y. A., Podevels, A. M., Kevany, B. M. \& Thomas, M. G. (2009). Biosynthesis of polyketide synthase extender units. Nat Prod Rep 26, 90-114.

Dulley, J. R. \& Grieve, P. A. (1975). A simple technique for eliminating interference by detergents in the Lowry method of protein determination. Anal Biochem 64, 136-141.

Epple, G., van der Drift, K. M. G. M., Thomas-Oates, J. \& Geiger, O. (1998). Characterization of a novel acyl carrier protein, RkpF, encoded by an operon involved in capsular polysaccharide biosynthesis in Sinorhizobium meliloti. J Bacteriol 180, 4950-4954.

Ferguson, G. P., Roop, R. M., II \& Walker, G. C. (2002). Deficiency of Sinorhizobium meliloti bacA mutant in alfalfa symbiosis correlates with the alteration of cell envelope. J Bacteriol 184, 5625-5632.

Ferguson, G. P., Datta, A., Carlson, R. W. \& Walker, G. C. (2005). Importance of unusually modified lipid A in Sinorhizobium stress resistance and legume symbiosis. Mol Microbiol 56, 68-80.

Florova, G., Kazanina, G. \& Reynolds, K. A. (2002). Enzymes involved in fatty acid and polyketide biosynthesis in Streptomyces glaucescens: role of FabH and FabD and their acyl carrier protein specificity. Biochemistry 41, 10462-10471.

Flugel, R. S., Hwangbo, Y., Lambalot, R. H., Cronan, J. E. \& Walsh, C. T. (2000). Holo-(acyl carrier protein) synthase and phosphopantetheinyl transfer in Escherichia coli. J Biol Chem 275, 959-978.

Galibert, F., Finan, T. M., Long, S. R., Pühler, A., Abola, P., Ampe, F., Barloy-Hubler, F., Barnett, M. J., Becker, A. \& other authors (2001). The composite genome of the legume symbiont Sinorhizobium meliloti. Science 293, 668-672. 
Geiger, O. \& López-Lara, I. M. (2002). Rhizobial acyl carrier proteins and their roles in the formation of bacterial cell surface components that are required for the development of nitrogen-fixing root nodules on legume hosts. FEMS Microbiol Lett 208, 153-162.

Geiger, O., Spaink, H. P. \& Kennedy, E. P. (1991). Isolation of the Rhizobium leguminosarum NodF nodulation protein: NodF carries a 4'-phosphopantetheine prosthetic group. J Bacteriol 173, 2872-2878.

Guo, X., Flores, M., Mavingui, P., Fuentes, S. I., Hernández, G., Dávila, G. \& Palacios, R. (2003). Natural genomic design in Sinorhizobium meliloti: novel genomic architectures. Genome Res 13, 1810-1817.

Haag, A. F., Wehmeier, S., Beck, S., Marlow, V. L., Fletcher, V., James, E. K. \& Ferguson, G. P. (2009). The Sinorhizobium meliloti LpxXL and AcpXL proteins play important roles in bacteroid development within alfalfa. J Bacteriol 191, 4681-4686.

Hofmann, K. (2000). A superfamily of membrane-bound $O$ acyltransferases with implications for Wnt signaling. Trends Biochem Sci 25, 111-112.

Jackowski, S. \& Rock, C. O. (1983). Ratio of active to inactive forms of acyl carrier protein in Escherichia coli. J Biol Chem 258, 1518615191.

Lambalot, R. H., Gehring, A. M., Flugel, R. S., Zuber, P., LaCelle, M., Marahiel, M. A., Reid, R., Khosla, C. \& Walsh, C. T. (1996). A new enzyme superfamily: the phosphopantetheinyl transferases. Chem Biol 3, 923-936.

López-Lara, I. M. \& Geiger, O. (2000). Expression and purification of four different acyl carrier proteins. Microbiology 146, 839-849.

Miller, J. H. (1972). Experiments in Molecular Genetics. Cold Spring Harbor, NY: Cold Spring Harbor Laboratory.

Olivares, J., Casadesus, J. \& Bedmar, E. J. (1980). Method for testing degree of infectivity of Rhizobium meliloti strains. Appl Environ Microbiol 39, 967-970.

Østeras, M., Boncompagni, E., Vincent, N., Poggi, M. C. \& Le Rudulier, D. (1998). Presence of a gene encoding choline sulfatase in Sinorhizobium meliloti bet operon: choline-O-sulfate is metabolised into glycine betaine. Proc Natl Acad Sci U S A 95, 11394-11399.

Ramos-Vega, A. L., Dávila-Martínez, Y., Sohlenkamp, C., ContrerasMartínez, S., Encarnación, S., Geiger, O. \& López-Lara, I. M. (2009). SMb20651 is another acyl carrier protein from Sinorhizobium meliloti. Microbiology 155, 257-267.

Rawlings, M. \& Cronan, J. E. (1992). The gene encoding Escherichia coli acyl carrier protein lies within a cluster of fatty acid biosynthetic genes. J Biol Chem 267, 5751-5754.

Reuhs, B. L., Geller, D. P., Kim, J. S., Fox, J. E., Kolli, V. S. \& Pueppke, S. G. (1998). Sinorhizobium fredii and Sinorhizobium meliloti produce structurally conserved lipopolysaccharides and strain-specific $\mathrm{K}$ antigens. Appl Environ Microbiol 64, 4930-4938.
Robertsen, B. K., Aman, P., Darvill, A. G., McNeil, M. \& Albersheim, P. (1981). Host-symbiont interactions. V. The structure of acidic extracellular polysaccharides secreted by Rhizobium leguminosarum and Rhizobium trifolii. Plant Physiol 67, 389-400.

Rock, C. O. (2008). Fatty acids and phospholipids metabolism in prokaryotes. In Biochemistry of Lipids, Lipoproteins and Membranes, 5th edn, pp 59-96. Edited by D. E. Vance \& J. E. Vance. Amsterdam: Elsevier.

Sambrook, J. \& Russell, D. R. (2001). Molecular Cloning: a Laboratory Manual. Cold Spring Harbor Laboratory, NY: Cold Spring Harbor Laboratory.

Schäfer, A., Tauch, A., Jäger, W., Kalinowski, J., Thierbach, G. \& Pühler, A. (1994). Small mobilizable multi-purpose cloning vectors derived from the Escherichia coli plasmids pK18 and pK19: selection of defined deletions in the chromosome of Corynebacterium glutamicum. Gene 145, 69-73.

Schägger, H. \& von Jagow, G. (1987). Tricine-sodium dodecyl sulfate-polyacrylamide gel electrophoresis for the separation of proteins in the range from 1 to $100 \mathrm{kDa}$. Anal Biochem 166, 368-379.

Schweizer, H. D. (1993). Small broad-host-range gentamicin resistance gene cassettes for site-specific insertion and deletion mutagenesis. Biotechniques 15, 831-834.

Sharypova, L. A., Niehaus, K., Scheidle, H., Holst, O. \& Becker, A. (2003). Sinorhizobium meliloti acpXL mutant lacks the C28 hydroxylated fatty acid moiety of lipid A and does not express a slow migrating form of lipopolysaccharide. J Biol Chem 278, 1294612954.

Sherwood, M. T. (1970). Improved synthetic medium for the growth of Rhizobium. J Appl Bacteriol 33, 708-713.

Simon, R., Priefer, U. \& Pühler, A. (1983). A broad host range mobilization system for in vivo genetic engineering: transposon mutagenesis in Gram negative bacteria. BioTechnology 1, 784-791.

Sohlenkamp, C., de Rudder, K. E. \& Geiger, O. (2004). Phosphatidylethanolamine is not essential for growth of Sinorhizobium meliloti on complex culture media. J Bacteriol 186, 1667-1677.

Studier, F. W., Rosenberg, A. H., Dunn, J. J. \& Dubendorff, J. W. (1990). Use of a T7 RNA polymerase to direct expression of cloned genes. Methods Enzymol 185, 60-89.

Sun, Y., Hong, H., Gillies, F., Spencer, J. B. \& Leadlay, P. F. (2008). Glyceryl-S-acyl carrier protein as an intermediate in the biosynthesis of tetronate antibiotics. ChemBioChem 9, 150-156.

Wu, K., Chung, L., Revill, W. P., Katz, L. \& Reeves, C. D. (2000). The FK520 gene cluster of Streptomyces hygroscopicus var. ascomyceticus (ATCC 14891) contains genes for biosynthesis of unusual polyketide extender units. Gene 251, 81-90.

Edited by: H.-M. Fischer 